\title{
Vulnerabilidad física y exposición ante la amenaza de movimientos en masa del Sistema de Agua Potable Culebrillas de la Ciudad de Cuenca
}

Physical vulnerability and exposure to the threat of mass movements of the Culebrillas Drinking Water Systems of the City of Cuenca

Gladys Marcela Moscoso Vintimlla. ${ }^{1}$, José Abelardo Paucar Camacho. ${ }^{2}$ \& José Luis Solano Peláez. ${ }^{3}$

Abstract.

DOI: https://doi.org/10.33262/cienciadigital.v5i2.1573

Introduction: In the city of Cuenca-Ecuador there are several drinking water supply systems, some of which are located in urban expansion areas and exposed to threats. Object: To analyze the physical vulnerability and exposure to the threat of mass movements of the Culebrillas drinking water system, which is located in the urban expansion zone and covers a part of the city. Methodology: A qualitative methodology was applied and an interview form was used with technicians from the Public Telecommunications Company, Drinking Water and Sewerage Company to collect information on each of the vulnerability indicators of the components of the system, which were weighted to obtain a physical vulnerability index, which allowed determining the level of vulnerability, the criteria for weighting the Delphi method was applied

\footnotetext{
1 Universidad Católica de Cuenca, Maestría Construcciones con mención en Administración de la Construcción Sustentable. Azuay Correo electrónico: gladys.moscoso.76@est.ucacue.edu.ec, gmmv81@ hotmail.com, https://orcid.org/0000-0002-7872-3482

2 Universidad Católica de Cuenca, Universidad Estatal de Bolívar, jose.paucarcamacho@ucacue.edu.ec, apaucar@ueb.edu.ec, http://orcid.org/0000-0003-2722-1850.

3 Universidad Católica de Cuenca, Profesor de la Unidad Académica de Ingeniería, Industria y Construcción. Supervisor Industrial, Ingeniero Químico y Especialista en Docencia Universitaria por la Universidad Católica de Cuenca; Magister en Sistemas de Gestión Ambiental por la Universidad de las Fuerzas Armadas - ESPE; estudiante de Doctorado en Ordenamiento Territorial y Desarrollo Sostenible de las Universidad de Cuyo - Argentina. Correo electrónico: jsolano@ucacue.edu.ec. http://orcid.org/0000-001-8388-0338.
} 
Aquaculture and Fisheries and Technical Secretariat for Risk Management. Results: The results indicate that the Culebrillas drinking water system in its components: catchment, has an index of 20 points representing the level of low vulnerability; driving, with 25 points equals low; treatment plant with 19,3 points represent low; distribution, which in turn is composed of the distribution reserve tanks with 25,2 points corresponding to low, and the distribution network with 48,8 points Driving, with fewer tanks and distribution network are in high level areas. Conclusion: This study constitutes a pilot model to evaluate the other systems that supplies the city of Cuenca, as well as, it could be replicated in other populated centers of the country.

Keywords: drinking water system, vulnerability, mass movement, exposure

\section{Resumen.}

Introducción: En la ciudad de Cuenca-Ecuador existen varios sistemas de abastecimiento de agua potable, algunos de los cuales se encuentran en zonas de expansión urbana y expuestos a amenazas. Objeto: Analizar la vulnerabilidad física y exposición ante la amenaza de movimientos en masa del sistema de agua potable Culebrillas, que se encuentra en la zona de expansión urbana y cubre una parte de la ciudad. Metodología: Se aplicó una metodología cualitativa y se utilizó una ficha de entrevista a técnicos de la Empresa Pública de Telecomunicaciones, Agua Potable y Alcantarillado para recolectar información de cada uno de los indicadores de vulnerabilidad de los componentes del sistema, que fueron ponderados para obtener un índice de vulnerabilidad física, el mismo que permitió determinar el nivel de vulnerabilidad, cuyos criterios para la ponderación se aplicó el método Delphi; mientras que, para establecer la exposición ante la amenaza de movimientos en masa de la infraestructura, se utilizó el mapa de movimiento en masa elaborado por el Ministerio de Agricultura, Ganadería, Acuacultura y Pesca y Secretaría Técnica de Gestión de Riesgos. Resultados: Los resultados indican que el sistema de agua potable Culebrillas en sus componentes: captación, posee un índice de 20 puntos que representa el nivel de vulnerabilidad bajo; conducción, con 25 puntos equivale a bajo; planta de tratamiento con 19,3 puntos representa bajo; distribución, que a su vez está compuesta por los tanques de reservas de distribución con 25,2 puntos que corresponde a bajo y la red de distribución con 48,4 puntos que representa medio; con respecto a la exposición a la amenaza movimiento en masa: la infraestructura de la captación-tanque, en su mayor parte la red de conducción, con menor número de tanques y la red de distribución se encuentran en zonas de nivel alto. Conclusión: El presente estudio constituye en un modelo piloto para evaluar los otros sistemas que abastece a la ciudad de Cuenca, así como, se podría replicar en otros centros poblados del país.

Palabras claves: sistemas de agua potable, vulnerabilidad, movimiento en masas, exposición. 


\section{Introducción.}

El mundo ha experimentado desastres devastadores que han causado graves pérdidas económicas y de vidas humanas que se estima en el 68,5\% de las pérdidas económicas mundiales entre 2005 y 2017. Los desastres naturales son motivo de gran preocupación: causaron un daño total de aproximadamente \$3,5 billones durante el siglo pasado, que es más que la inversión global en desarrollo de infraestructura en 2014, como menciona (Sweya \& Wilkinson, 2021) las infraestructuras seguirán sufriendo si no se mejora la resiliencia.

El Ecuador por sus características geográficas se encuentra expuesto a múltiples amenazas y fenómenos naturales, que se vuelven destructivos, en buena parte por la falta de aplicación de la variable "riesgo natural" en las actividades de desarrollo y en especial en la planificación y utilización adecuados del territorio, respetando a la naturaleza y a sus fenómenos.(Carrizosa, M., Cohen, M., Gutman, M., Leite, F., López, D., Nesprias, J., ... Versace, 2019).

La administración del riesgo de desastres debe integrarse o transversalizarse en la gestión del desarrollo desde los diferentes ámbitos y ordenar el territorio apropiadamente, evitando la generación de nuevos riesgos y la reducción de daños y pérdidas causados por desastres, a través del control de las condiciones de riesgo existentes y de la transferencia del mismo.(Servicio Nacional de Gestión de Riesgos y Emergencias, 2019).

La ciudad de Cuenca en Ecuador, presenta una aproximación a la resiliencia urbana caracterizada, en mayor medida que los demás casos, por el componente ambiental. En su larga historia, desde el asentamiento precolombino hasta la actualidad, la población ha demostrado un abordaje del riesgo de inundación que se basa en la preservación ecológica y en un alto grado de conciencia y respeto por la variabilidad de los ríos. Mientras que las estrategias convencionales para manejar los ríos urbanos se han enfocado en controlar los flujos con la construcción de muros de concreto y canalizaciones, por otro lado ha demostrado conciencia social de los riesgos y los beneficios del río. Históricamente y hasta la fecha, los ríos han ofrecido una gran variedad de funciones, actuando como un punto de encuentro para las interacciones sociales. Así también se depende del sistema fluvial no solo para el agua potable, sino también para la generación de energía hidroeléctrica, lo que vuelve importante a la región montañosa circundante, cuyas corrientes de agua alimentan a los ríos, es fundamental para las estrategias de desarrollo a lo largo plazo de la urbe. (Carrizosa, M., Cohen, M., Gutman, M., Leite, F., López, D., Nesprias, J., ... Versace, 2019)

El análisis y la evaluación de riesgos para el servicio de agua integrada relacionados con peligros naturales y/o de origen humano, son amenazas en las cuales se basa la ecuación que correlaciona el riesgo con la probabilidad de ocurrencia de un evento adverso, es decir, vulnerabilidad y consecuencias. (Gnavi, L., Taddia, G., \& Russo, 2015). 
El abastecimiento de agua potable es un factor importante dentro de la sociedad ya que provee de líquido vital a los habitantes y garantiza la calidad de vida por lo tanto su correcto funcionamiento es prioritario, su ausencia puede causar impactos dentro de la salud, por ende, se hace necesario contar con un análisis de vulnerabilidad de esta infraestructura desde su captación, conducción, tratamiento y distribución, con el fin de proyectarse a un adecuado manejo y administración de las instalaciones.

La Empresa Pública Municipal de Telecomunicaciones, Agua Potable, Alcantarillado y Saneamiento de Cuenca (Etapa EP, 2021) cuenta con el sistema de distribución de agua potable conformado por 22 zonas de presión, cada una con un centro de reserva con la posibilidad de interconexión en casos de emergencia. El sistema es efectuado completamente a gravedad, salvo dos sectores altos de la ciudad. Dependiendo del caudal que produce cada una de las plantas, éstas abastecen a un número definido de sectores, agrupándose en 4 zonas urbanas (El Cebollar, Sustag, Tixán, San Pedro).

El sistema Culebrillas se abastece desde el río del mismo nombre, la planta de tratamiento formada por tres unidades parcialmente comunicadas se encuentra en el sector de San Pedro del Cebollar y es la que abastece al sistema. La primera planta (planta antigua, 1996) construida de hormigón armado, tiene una capacidad de 30 litros/segundo y es de tipo convencional. La segunda planta es metálica prefabricada y es de tipo convencional, tiene una capacidad de 15 litros/segundo, entro en funcionamiento en el 2009, la tercera planta (planta nueva) es metálica prefabricada y con tratamiento de aireación filtración con una capacidad de 150 litros/segundo, fue construida entre el 2014 y 2015. (Piedra, 2017).

Según (Jimenez, 2013) un sistema de abastecimiento de agua potable, tiene como finalidad primordial, la de entregar a los habitantes de una localidad, agua en cantidad y calidad adecuada para satisfacer sus necesidades, ya que como se sabe los seres humanos estamos compuestos en un $70 \%$ de agua, por lo que este líquido es vital para la supervivencia.

Un sistema moderno de abastecimiento de agua como se expone en (Comisión Nacional del Agua, 2007) se compone de instalaciones para la captación, almacenamiento, conducción, bombeo, tratamiento y distribución. Las obras de captación y almacenamiento permiten reunir las aguas aprovechables de ríos, manantiales y depósitos subterráneos; incluyen actividades como el desarrollo y cuidado de la cuenca de aportación, pozos y manantiales, así como la construcción de presas y de galerías filtrantes. La conducción incluye canales y acueductos, así como instalaciones complementarias de bombeo para transportar el agua desde la fuente hasta el centro de distribución. El tratamiento es la serie de procesos que le dan al agua la calidad requerida. Finalmente, la distribución es dotar de agua al usuario, para su consumo.

Los métodos cualitativos generalmente requieren menos insumos datos; la evaluación de riesgo cualitativa más común es el riesgo clasificación. La estimación de riesgos con 
matrices de riesgos es una herramienta útil y herramienta eficiente y fácil de comprender y presentar datos.(Gnavi, L., Taddia, G., \& Russo, 2015)

Los movimiento en masa representan los principales peligros geológicos en todo el mundo y se define como "grandes masas de roca y suelo que caen, se deslizan o fluyen" (Paucar, 2016) de (Pilatasig, 2009, lámina 8).

La susceptibilidad está definida como la propensión o tendencia de una zona a ser afectada o hallarse bajo la influencia de un proceso determinado, en este caso movimientos en masa. La estimación de la susceptibilidad se basa en la correlación de los principales factores (intrínsecos) que contribuyen en la formación de movimientos en masa. Los mapas de susceptibilidad, se realizan a partir de datos cartográficos de tipo topográfico, geomorfológico, litológico, estructural, vegetación, usos de suelos y otros.(Villacorta et al., 2012).

Según (Decisión, 2018) la Vulnerabilidad son las condiciones determinadas por factores o procesos físicos, sociales, económicos, y ambientales, que aumentan la susceptibilidad de una persona, comunidad, bienes o sistemas al impacto de amenazas

El presente estudio contiene la evaluación cualitativa de vulnerabilidad física del Sistema Culebrillas de Agua Potable de la ciudad de Cuenca; puesto que la importancia de analizar la exposición a la amenaza, de los componentes del sistema y en conjunto, a los movimientos en masa, es una manera identificar zonas de riesgo con lo cual nos ayuda a tomar acciones preventivas en los componentes ya construidos e identificar los lugares en los cuales no se deberían extender el crecimiento de los centros poblados.

\section{Metodología.}

Las redes de agua potable como parte de las infraestructuras esenciales permiten la funcionalidad de un territorio en "tiempos normales" y en períodos de afectación por "desastres", su interrupción o desabastecimiento puede provocar problemas críticos en la salubridad, higiene y la salud de la población (Paucar, 2016). Por consiguiente, es necesario realizar la evaluación de la vulnerabilidad, que de acuerdo con la Organización Panamericana de la Salud / Organización Mundial de la Salud (OPS/OMS) "es la susceptibilidad a la pérdida de un elemento o conjunto de elementos como resultado de la ocurrencia de un desastre", por lo tanto, pueden afectar a la normal distribución de agua potable (OPS/OMS, 1998).

La vulnerabilidad de los sistemas de agua potable ante los desastres en su mayoría se encuentra ligado a los componentes físicos del sistema. Es por ello que, que se evalúo la vulnerabilidad física y exposición a la amenaza de movimientos en masa (deslizamientos, caída de bloques y flujos) que son eventos cuya masa generalmente se desplaza en conjunto, puede seguir en movimiento a lo largo de cientos de metros y alcanzar velocidades muy elevadas, los mismos que pueden afectar a las infraestructuras que se 
encuentran en su zona de influencia (Vivienda, 2003); además, que se pueden presentar con mayor recurrencia (anualmente) en períodos lluvioso.

La ciudad de Cuenca es uno de los centros urbanos más poblados de Ecuador, el servicio de agua potable es otorgada a través de Empresa Pública de Telecomunicaciones, Agua Potable y Alcantarillado (ETAPA E.P.) que posee un total de 152.214 usuarios, que se abastece a través de seis sistemas de agua: Chulco Soroche, Culebrillas, Yanauncay, Tomebamba, Machángara, Sayausí. Para el presente estudio, se estableció como modelo piloto al sistema de agua potable Culebrillas, que cubre a la población de la parte norte de la zona de expansión urbana, con un total de 7.755 usuarios que representa el 5,09\% de cobertura; adicionalmente, los técnicos municipales, consideran que es necesario evaluar la vulnerabilidad y exposición ya que cubre una zona que está en proceso de expansión y consolidación urbana, por lo tanto, se requerirá ampliar la cobertura en la que se debe incluir estrategias y medidas de prevención y reducción (Etapa EP, 2021).

\section{Metodología para la evaluación de la vulnerabilidad física a movimientos en masa}

El análisis de la vulnerabilidad física del sistema de agua potable Culebrillas se realizó mediante una metodología cualitativa, que se basa en la descripción de las condiciones o características físicas de las infraestructuras de cada componente del sistema ((PNUD)., 2012). En este caso, en el componente de captación, se evalúo el tanque; en la conducción, la red de tubería; en el tratamiento, los tanques; en la distribución los tanques de reserva y la red de tubería de distribución.

Para cada uno de los componentes del sistema de agua se consideró siete variables: 1) estudios técnicos para estabilidad del terreno, 2) material de construcción, 3) antigüedad, 4) estándares de diseño y construcción, 5) mantenimiento, 6) estado actual y 7) proyectos y/o medidas de reducción de riesgos. A través del método Delphi (criterio basado en expertos), para los indicadores de cada componente, es estableció escalas cualitativas, a las mismas que se estableció valores entre 1 a 10, según su condición o característica física que tiene menor o mayor incidencia en la vulnerabilidad; de igual forma, a cada indicador se asignó un peso de ponderación, distribuidos entre 1 a 10) de acuerdo a la importancia que tendría en la funcionalidad y vulnerabilidad de cada componente del sistema. Finalmente, al multiplicar el valor del indicador por el peso de ponderación se obtiene el valor máximo, cuya sumatoria da como resultado el Índice de Vulnerabilidad Física que a su vez determina el nivel de vulnerabilidad del componente del sistema.

A continuación, en las tablas del 1 al 5 se presenta los criterios de ponderación de vulnerabilidad ante la amenaza de movimientos en masa de cada uno de los componentes del sistema de agua potable Culebrillas, en los mismos que se aplicó el proceso metodológico descrito en el párrafo anterior. 


\begin{tabular}{|c|c|c|c|c|c|}
\hline Componente & Indicadores & Escala cualitativa & $\begin{array}{c}\text { Valor } \\
\text { indicador }\end{array}$ & Peso ponderación & $\begin{array}{l}\text { Valor } \\
\text { máximo }\end{array}$ \\
\hline \multirow{20}{*}{ Captación } & \multirow[t]{2}{*}{$\begin{array}{l}\text { Estudios técnicos } \\
\text { para cimentación }\end{array}$} & $\begin{array}{l}\text { Se realizó estudios y } \\
\text { aplicó } \\
\text { Se realizó estudios, pero } \\
\text { no se aplicó } \\
\text { No se realizó estudios }\end{array}$ & $\begin{array}{c}5,0 \\
10,0\end{array}$ & \multirow[t]{2}{*}{1,0} & 10,0 \\
\hline & & Hormigón & 1,0 & & \multirow{3}{*}{25,0} \\
\hline & \multirow{2}{*}{$\begin{array}{l}\text { Material de } \\
\text { construcción }\end{array}$} & Asbesto cemento & 5,0 & \multirow[t]{2}{*}{2,5} & \\
\hline & & $\begin{array}{l}\text { Mampostería de piedra } \\
\text { y/o de ladrillo }\end{array}$ & 10,0 & & \\
\hline & \multirow{3}{*}{ Antigüedad } & 0 a 25 años & 1,0 & \multirow{3}{*}{1,5} & \multirow{3}{*}{15,0} \\
\hline & & 25 a 50 años & 5,0 & & \\
\hline & & $>$ de 50 años & 10,0 & & \\
\hline & \multirow{4}{*}{$\begin{array}{l}\text { Estándares de diseño } \\
\text { y construcción }\end{array}$} & Ninguna & 10,0 & \multirow{4}{*}{1,0} & \multirow{3}{*}{10,0} \\
\hline & & Norma IEOS & 5,0 & & \\
\hline & & Norma MIDUVI o local & 1,0 & & \\
\hline & & Planificado & 1,0 & & \multirow{3}{*}{15,0} \\
\hline & \multirow[t]{3}{*}{ Mantenimiento } & Esporádico & 5,0 & \multirow[t]{2}{*}{1,5} & \\
\hline & & Ninguno & 10,0 & & \\
\hline & & Bueno & 1,0 & \multirow{3}{*}{1,0} & \multirow{3}{*}{10,0} \\
\hline & \multirow[t]{2}{*}{ Estado actual } & Regular & 5,0 & & \\
\hline & & Malo & 10,0 & & \\
\hline & \multirow{3}{*}{$\begin{array}{l}\text { Proyectos y/o } \\
\text { medidas de reducción } \\
\text { de riesgos }\end{array}$} & Se planifica y ejecuta & 1,0 & \multirow{3}{*}{1,5} & \multirow{3}{*}{15,0} \\
\hline & & $\begin{array}{l}\text { Se planifica, pero no se } \\
\text { ejecuta }\end{array}$ & 5,0 & & \\
\hline & & No se planifica ni ejecuta & 10,0 & & \\
\hline & \multicolumn{3}{|c|}{ Índice de vulnerabilidad } & 10,0 & 100,0 \\
\hline
\end{tabular}

Tabla 1. Criterios para la ponderación de la vulnerabilidad física del Componente Captación Fuente: Elaboración propia

\begin{tabular}{|c|c|c|c|c|c|}
\hline Componente & Indicadores & Escala cualitativa & $\begin{array}{c}\text { Valor } \\
\text { indicador }\end{array}$ & $\begin{array}{c}\text { Peso } \\
\text { ponderación }\end{array}$ & $\begin{array}{l}\text { Valor } \\
\text { máximo }\end{array}$ \\
\hline \multirow{21}{*}{ Conducción } & \multirow{3}{*}{$\begin{array}{l}\text { Estudios técnicos } \\
\text { para estabilidad } \\
\text { del terreno }\end{array}$} & Se realizó estudios y aplicó & 1,0 & \multirow{3}{*}{1,0} & \multirow{3}{*}{10,0} \\
\hline & & Se realizó estudios, pero no se aplicó & 5,0 & & \\
\hline & & No se realizó estudios & 10,0 & & \\
\hline & \multirow{3}{*}{$\begin{array}{l}\text { Material de } \\
\text { construcción } \\
\text { (tubería) }\end{array}$} & $\mathrm{PVC}$ & 5,0 & \multirow{3}{*}{2,5} & \multirow{3}{*}{25,0} \\
\hline & & Hierro Dúctil (HD) & 1,0 & & \\
\hline & & Asbesto o cemento & 10,0 & & \\
\hline & \multirow{3}{*}{ Antigüedad } & 0 a 25 años & 1,0 & \multirow{3}{*}{1,5} & \multirow{3}{*}{15,0} \\
\hline & & 25 a 50 años & 5,0 & & \\
\hline & & $>$ de 50 años & 10,0 & & \\
\hline & \multirow{3}{*}{$\begin{array}{l}\text { Estándares de } \\
\text { diseño y } \\
\text { construcción }\end{array}$} & Ninguna & 10,0 & \multirow{3}{*}{1,0} & \multirow{3}{*}{10,0} \\
\hline & & Norma IEOS & 5,0 & & \\
\hline & & Norma MIDUVI o local & 1,0 & & \\
\hline & \multirow{3}{*}{ Mantenimiento } & Planificado & 1,0 & \multirow{3}{*}{1,5} & \multirow{3}{*}{15,0} \\
\hline & & Esporádico & 5,0 & & \\
\hline & & Ninguno & 10,0 & & \\
\hline & \multirow{3}{*}{ Estado actual } & Bueno & 1,0 & \multirow{3}{*}{1,0} & \multirow{3}{*}{10,0} \\
\hline & & Regular & 5,0 & & \\
\hline & & Malo & 10,0 & & \\
\hline & \multirow{3}{*}{$\begin{array}{l}\text { Proyectos y/o } \\
\text { medidas de } \\
\text { reducción de } \\
\text { riesgos }\end{array}$} & Se planifica y ejecuta & 1,0 & \multirow{3}{*}{1,5} & \multirow{3}{*}{15,0} \\
\hline & & Se planifica, pero no se ejecuta & 5,0 & & \\
\hline & & No se planifica ni ejecuta & 10,0 & & \\
\hline
\end{tabular}

Tabla 2. Criterios para la ponderación de la vulnerabilidad física del Componente Conducción Fuente: Elaboración propia 


\begin{tabular}{|c|c|c|c|c|c|}
\hline Componente & Indicadores & Escala cualitativa & $\begin{array}{c}\text { Valor } \\
\text { indicador }\end{array}$ & $\begin{array}{c}\text { Peso } \\
\text { ponderación }\end{array}$ & $\begin{array}{l}\text { Valor } \\
\text { máximo }\end{array}$ \\
\hline \multirow{26}{*}{ Tratamiento } & \multirow{3}{*}{$\begin{array}{l}\text { Estudios técnicos } \\
\text { para cimentación }\end{array}$} & Se realizó estudios y aplicó & 1,0 & \multirow{3}{*}{1,0} & \multirow{3}{*}{10,0} \\
\hline & & $\begin{array}{l}\text { Se realizó estudios, pero no se } \\
\text { aplicó }\end{array}$ & 5,0 & & \\
\hline & & No se realizó estudios & 10,0 & & \\
\hline & \multirow{7}{*}{$\begin{array}{l}\text { Material de } \\
\text { construcción }\end{array}$} & Planta de hormigón & 1,0 & \multirow{7}{*}{2,5} & \multirow{7}{*}{25,0} \\
\hline & & Planta de asbesto cemento & 5,0 & & \\
\hline & & Planta de mampostería de & 10,0 & & \\
\hline & & $\begin{array}{l}\text { ladrillo } \\
\text { Planta prefabricada }\end{array}$ & 5,0 & & \\
\hline & & Planta metálica & 5,0 & & \\
\hline & & Planta DAFFI: Acero & 10 & & \\
\hline & & Inoxidable-Aceros y hormigón & 1,0 & & \\
\hline & \multirow{3}{*}{ Antigüedad } & 0 a 25 años & 1,0 & \multirow{3}{*}{1,5} & \multirow{3}{*}{15,0} \\
\hline & & 25 a 40 años & 5,0 & & \\
\hline & & $>$ de 40 años & 10,0 & & \\
\hline & \multirow{4}{*}{$\begin{array}{l}\text { Estándares de } \\
\text { diseño y } \\
\text { construcción }\end{array}$} & Ninguna & 10,0 & \multirow{4}{*}{1,0} & \multirow{3}{*}{10,0} \\
\hline & & Norma IEOS & 5,0 & & \\
\hline & & Norma MIDUVI o local & 1,0 & & \\
\hline & & Planificado & 1,0 & & \multirow{3}{*}{15,0} \\
\hline & \multirow[t]{3}{*}{ Mantenimiento } & Esporádico & 5,0 & \multirow[t]{2}{*}{1,5} & \\
\hline & & Ninguno & 10,0 & & \\
\hline & & Bueno & 1,0 & \multirow{3}{*}{1,0} & \multirow{3}{*}{10,0} \\
\hline & \multirow[t]{2}{*}{ Estado actual } & Regular & 5,0 & & \\
\hline & & Malo & 10,0 & & \\
\hline & \multirow{3}{*}{$\begin{array}{l}\text { Proyectos y/o } \\
\text { medidas de } \\
\text { reducción de } \\
\text { riesgos }\end{array}$} & Se planifica y ejecuta & 1,0 & \multirow{3}{*}{1,5} & \multirow{3}{*}{15,0} \\
\hline & & Se planifica, pero no se ejecuta & 5,0 & & \\
\hline & & No se planifica ni ejecuta & 10,0 & & \\
\hline & \multicolumn{3}{|c|}{ Índice de vulnerabilidad } & $\mathbf{1 0 , 0}$ & 100,0 \\
\hline
\end{tabular}

Tabla 3. Criterios para la ponderación de la vulnerabilidad física del componente tratamiento Fuente: Elaboración propia

\begin{tabular}{|c|c|c|c|c|c|}
\hline Componente & Indicadores & Escala cualitativa & $\begin{array}{c}\text { Valor } \\
\text { indicador }\end{array}$ & $\begin{array}{c}\text { Peso } \\
\text { ponderación }\end{array}$ & $\begin{array}{l}\text { Valor } \\
\text { máximo }\end{array}$ \\
\hline \multirow{18}{*}{$\begin{array}{l}\text { Tanques de } \\
\text { distribución }\end{array}$} & \multirow{3}{*}{$\begin{array}{l}\text { Estudios técnicos } \\
\text { para cimentación }\end{array}$} & Se realizó estudios y aplicó & 1,0 & \multirow{3}{*}{1,0} & \multirow{3}{*}{10,0} \\
\hline & & Se realizó estudios, pero no se aplicó & 5,0 & & \\
\hline & & No se realizó estudios & 10,0 & & \\
\hline & \multirow{4}{*}{$\begin{array}{l}\text { Material de } \\
\text { construcción }\end{array}$} & Hormigón Armado & 1,0 & \multirow{4}{*}{2,5} & \multirow{4}{*}{25,0} \\
\hline & & Ferro cemento & 5,0 & & \\
\hline & & Mampostería de ladrillo & 10,0 & & \\
\hline & & Mampostería de piedra & 10,0 & & \\
\hline & \multirow{3}{*}{ Antigüedad } & 0 a 25 años & 1,0 & \multirow{3}{*}{1,5} & \multirow{3}{*}{15,0} \\
\hline & & 25 a 40 años & 5,0 & & \\
\hline & & $>$ de 40 años & 10,0 & & \\
\hline & \multirow{3}{*}{$\begin{array}{l}\text { Estándares de } \\
\text { diseño y } \\
\text { construcción }\end{array}$} & Ninguna & 10,0 & \multirow{3}{*}{1,0} & \multirow{3}{*}{10,0} \\
\hline & & Norma IEOS & 5,0 & & \\
\hline & & Norma MIDUVI o local & 1,0 & & \\
\hline & \multirow{3}{*}{ Mantenimiento } & Planificado & 1,0 & \multirow{3}{*}{1,5} & \multirow{3}{*}{15,0} \\
\hline & & Esporádico & 5,0 & & \\
\hline & & Ninguno & 10,0 & & \\
\hline & \multirow{2}{*}{ Estado actual } & Bueno & 1,0 & \multirow{2}{*}{1,0} & \multirow{2}{*}{10,0} \\
\hline & & Regular & 5,0 & & \\
\hline
\end{tabular}




\begin{tabular}{llccc} 
& Malo & 10,0 & & \\
$\begin{array}{llcl}\text { Proyectos y/o } \\
\text { medidas de } \\
\text { reducción de }\end{array}$ Se planifica y ejecuta & 1,0 & & \\
riesgos & Se planifica, pero no se ejecuta & 5,0 & 1,5 & 15,0 \\
Índice de vulnerabilidad & 10,0 & & \\
\hline
\end{tabular}

Tabla 4. Criterios para la ponderación de la vulnerabilidad física del componente tanques de distribución

Fuente: Elaboración propia

\begin{tabular}{|c|c|c|c|c|c|}
\hline Componente & Indicadores & Escala cualitativa & $\begin{array}{c}\text { Valor } \\
\text { indicador }\end{array}$ & $\begin{array}{c}\text { Peso } \\
\text { ponderación }\end{array}$ & $\begin{array}{l}\text { Valor } \\
\text { máximo }\end{array}$ \\
\hline \multirow{24}{*}{$\begin{array}{l}\text { Red de } \\
\text { distribución }\end{array}$} & \multirow{3}{*}{$\begin{array}{l}\text { Estudios técnicos } \\
\text { para estabilidad del } \\
\text { terreno }\end{array}$} & Se realizó estudios y aplicó & 1,0 & \multirow{3}{*}{1,0} & \multirow{3}{*}{10,0} \\
\hline & & Se realizó estudios, pero no se aplicó & 5,0 & & \\
\hline & & No se realizó estudios & 10,0 & & \\
\hline & \multirow{5}{*}{$\begin{array}{l}\text { Material de } \\
\text { construcción (tubería) }\end{array}$} & $\mathrm{PVC}$ & 5,0 & \multirow{5}{*}{2,5} & \multirow{5}{*}{25,0} \\
\hline & & PVC-TOM & 1,0 & & \\
\hline & & Hierro Dúctil (HD) & 1,0 & & \\
\hline & & Politubo & 10,0 & & \\
\hline & & Asbesto o cemento & 10,0 & & \\
\hline & \multirow{3}{*}{ Antigüedad } & 0 a 25 años & 1,0 & \multirow{3}{*}{1,5} & \multirow{3}{*}{15,0} \\
\hline & & 25 a 40 años & 5,0 & & \\
\hline & & $>$ de 40 años & 10,0 & & \\
\hline & \multirow{3}{*}{$\begin{array}{l}\text { Estándares de diseño } \\
\text { y construcción }\end{array}$} & Ninguna & 10,0 & \multirow{3}{*}{1,0} & \multirow{3}{*}{10,0} \\
\hline & & Norma IEOS & 5,0 & & \\
\hline & & Norma MIDUVI o local & 1,0 & & \\
\hline & \multirow{3}{*}{ Mantenimiento } & Planificado & 1,0 & \multirow{3}{*}{1,5} & \multirow{3}{*}{15,0} \\
\hline & & Esporádico & 5,0 & & \\
\hline & & Ninguno & 10,0 & & \\
\hline & \multirow{3}{*}{ Estado actual } & Bueno & 1,0 & \multirow{3}{*}{1,0} & \multirow{3}{*}{10,0} \\
\hline & & Regular & 5,0 & & \\
\hline & & Malo & 10,0 & & \\
\hline & \multirow{3}{*}{$\begin{array}{l}\text { Proyectos y/o } \\
\text { medidas de reducción } \\
\text { de riesgos }\end{array}$} & Se planifica y ejecuta & 1,0 & \multirow{3}{*}{1,5} & \multirow{3}{*}{15,0} \\
\hline & & Se planifica, pero no se ejecuta & 5,0 & & \\
\hline & & No se planifica ni ejecuta & 10,0 & & \\
\hline & \multicolumn{2}{|c|}{ Índice de vulnerabilidad } & & 10,0 & 100,0 \\
\hline
\end{tabular}

Tabla 5. Criterios para la ponderación de la vulnerabilidad física del componente red de distribución

Fuente: Elaboración propia

Los valores de los índices de cada componente del sistema permiten determinar el nivel de vulnerabilidad en base a los criterios que se presentan en la tabla 6 .

\begin{tabular}{ll}
\hline \multicolumn{1}{c}{ Rangos de índice } & \multicolumn{1}{c}{$\begin{array}{c}\text { Nivel de vulnerabilidad y color } \\
\text { de representación }\end{array}$} \\
\hline De 1 a 33 puntos & Baja \\
De 34 a 66 puntos & Media \\
De 67 a 100 puntos & Alta \\
\hline
\end{tabular}

Tabla 6. Rangos de índices y nivel de vulnerabilidad para el sistema de agua potable Culebrillas Fuente: Elaboración propia 
Para la recopilación de información de cada uno de los indicadores de evaluación de la vulnerabilidad de los componentes del sistema de agua potable Culebrillas, se aplicó una ficha de entrevista a 2 técnicos responsables del mantenimiento y operación del sistema que laboran y poseen experiencia entre 15 a 25 años en la empresa pública ETAPA E.P.

\section{Metodología para el análisis de movimientos en masa}

Para el análisis de la exposición de la infraestructura física de los componentes del sistema de agua Culebrilla a la amenaza de movimientos en masa se ha considerado dos etapas:

La primera recopilación de información existente sobre el mapa de amenaza de los movimientos en masa del Ecuador, en formato shape file a escala 1:250.000, elaborado por el Ministerio de Agricultura, Ganadería Acuacultura y Pesca - MAGAP y la Secretaría Técnica de Gestión de Riesgos - STGR, actualizada al año 2014 y disponible en la página web del Servicio Nacional de Información(MAGAP, 2014). Además, se recopiló archivos en formato shape file, de la ciudad de Cuenca, proporcionada por la Empresa Pública de Telecomunicaciones, Agua Potable y Alcantarillado ETAPA E.P. (Gerencia de Agua Potable y Saneamiento).

La segunda fase, se procesó la información, el análisis y representación de mapas temáticos mediante el Sistema de Información Geográfica a través del software ARC GIS (10.1), con licencia de la Universidad Católica de Cuenca. Adicionalmente, se debe mencionar que, de igual forma, se representan la vulnerabilidad en el software antes mencionado.

En la metodología utilizada para el análisis de movimiento en masa se ha considerado dos etapas:

La primera recopilación de información existente sobre los movimientos en masa en el Ecuador. (MAGAP, 2014), información geográfica del Sistema Culebrillas de la Ciudad de Cuenca, proporcionada por la Empresa Pública de Telecomunicaciones, Agua Potable y Alcantarillado (Gerencia de Agua Potable y Saneamiento).

La segunda fase, se procesó la información, el análisis y representación de mapas temáticos mediante el Sistema de Información Geográfica a través del software ARC GIS (10.1), con licencia de la Universidad Católica de Cuenca. Cabe mencionar que, para establecer el nivel de exposición, en base al mapa del MAGAP y STGR, se consideraron las zonas de nivel alto, medio (se unió el nivel mediana y moderada por ser niveles de la misma categoría) y baja. Adicionalmente, se debe mencionar que, de igual forma, se representan la vulnerabilidad en el software antes mencionado. 


\section{Resultados.}

\section{Análisis de vulnerabilidad y exposición del componente captación}

Se realizó el análisis del componente captación, el tanque fue construido en el 2007, se realizó estudios geotécnicos para la cimentación, su estructura es de hormigón armado y se construyó un muro de cimentación, es por ello que, se obtuvo un índice de vulnerabilidad física de 20 puntos que representa el nivel vulnerabilidad bajo como se observa en la tabla 7; con respecto a la exposición a los movimientos en masa, el tanque de captación se encuentra en una zona de nivel alta (ver tabla 12 y mapa 1).

\begin{tabular}{|c|c|c|c|c|c|c|}
\hline $\begin{array}{c}\text { Componente: } \\
\text { captación }\end{array}$ & $\begin{array}{c}\text { Número } \\
\text { de tanques }\end{array}$ & Indicadores & $\begin{array}{l}\text { Condición del } \\
\text { sistema }\end{array}$ & $\begin{array}{c}\text { Valor de } \\
\text { indicador }\end{array}$ & $\begin{array}{c}\text { Peso } \\
\text { ponderación }\end{array}$ & $\begin{array}{c}\text { Valor } \\
\text { máximo }\end{array}$ \\
\hline \multirow{7}{*}{ Captación } & \multirow[t]{7}{*}{ 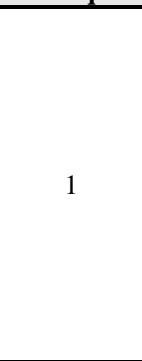 } & $\begin{array}{l}\text { Estudios técnicos para } \\
\text { cimentación }\end{array}$ & $\begin{array}{l}\text { Se realizó } \\
\text { estudios y } \\
\text { aplicó }\end{array}$ & 1 & 1,0 & 1,0 \\
\hline & & Material de construcción & Hormigón & 1 & 2,5 & 2,5 \\
\hline & & Antigüedad & 0 a 25 años & 1 & 1,5 & 1,5 \\
\hline & & $\begin{array}{l}\text { Estándares de diseño y } \\
\text { construcción }\end{array}$ & Norma IEOS & 5 & 1,0 & 5,0 \\
\hline & & Mantenimiento & Esporádico & 5 & 1,5 & 7,5 \\
\hline & & Estado actual & Bueno & 1 & 1,0 & 1,0 \\
\hline & & $\begin{array}{l}\text { Proyectos y/o medidas } \\
\text { de reducción de riesgos }\end{array}$ & $\begin{array}{l}\text { Se planifica y } \\
\text { ejecuta }\end{array}$ & 1 & 1,5 & 1,5 \\
\hline \multirow{2}{*}{ Total } & \multirow{2}{*}{1} & Índice de vulnerabilidad & & & \multirow[t]{2}{*}{10,0} & 20,0 \\
\hline & & Nivel de vulnerabilidad & & & & Bajo \\
\hline
\end{tabular}

Tabla 7. Resultados Análisis de vulnerabilidad física del componente captación Fuente: Elaboración propia

\section{Análisis de vulnerabilidad y exposición del componente conducción}

Al analizar la red de conducción es del año 2007, en la tubería principal es de Hierro Dúctil, por lo que su índice vulnerabilidad es de 20 puntos (nivel bajo), además, posee tubería PVC en mínima extensión que influye en el índice que es de 30 puntos (bajo); el índice de vulnerabilidad física promedio de este componente es de 25 puntos que equivale al nivel de vulnerabilidad bajo como se observa en la tabla 8. Sin embargo, un 51,7\% de la tubería se encuentra en una zona de nivel de exposición a movimiento en masa alta y 45,4\% nivel media, como se observa en la tabla 12 y mapa 1.

\begin{tabular}{|c|c|c|c|c|c|c|}
\hline $\begin{array}{c}\text { Componente: } \\
\text { conducción }\end{array}$ & $\begin{array}{c}\begin{array}{c}\text { Longitud } \\
\text { en km }\end{array} \\
\end{array}$ & Indicadores & $\begin{array}{c}\begin{array}{c}\text { Condición del } \\
\text { sistema }\end{array} \\
\end{array}$ & $\begin{array}{l}\text { Valor de } \\
\text { indicador }\end{array}$ & $\begin{array}{c}\text { Peso } \\
\text { ponderación }\end{array}$ & Valor máximo \\
\hline \multirow{7}{*}{$\begin{array}{l}\text { Tubería de } \\
\text { conducción }\end{array}$} & \multirow{7}{*}{6,89} & $\begin{array}{l}\text { Estudios técnicos } \\
\text { para estabilidad del } \\
\text { terreno }\end{array}$ & $\begin{array}{l}\text { Se realizó estudios } \\
\text { y aplicó }\end{array}$ & - & 1,0 & 1,0 \\
\hline & & $\begin{array}{l}\text { Material de } \\
\text { construcción } \\
\text { (tubería) }\end{array}$ & $\begin{array}{l}\text { Hierro Dúctil } \\
\text { (HD) }\end{array}$ & 1 & 2,5 & 2,5 \\
\hline & & Antigüedad & $\begin{array}{l}0 \text { a } 25 \text { años (año } \\
2007 \text { ) }\end{array}$ & 1 & 1,5 & 1,5 \\
\hline & & $\begin{array}{l}\text { Estándares de } \\
\text { diseño y } \\
\text { construcción }\end{array}$ & Norma IEOS & 5 & 1,0 & 5,0 \\
\hline & & Mantenimiento & Esporádico & 5 & 1,5 & 7,5 \\
\hline & & Estado actual & Bueno & 1 & 1,0 & 1,0 \\
\hline & & $\begin{array}{l}\text { Proyectos y/o } \\
\text { medidas de }\end{array}$ & $\begin{array}{l}\text { Se planifica y } \\
\text { ejecuta }\end{array}$ & 1 & 1,5 & 1,5 \\
\hline
\end{tabular}




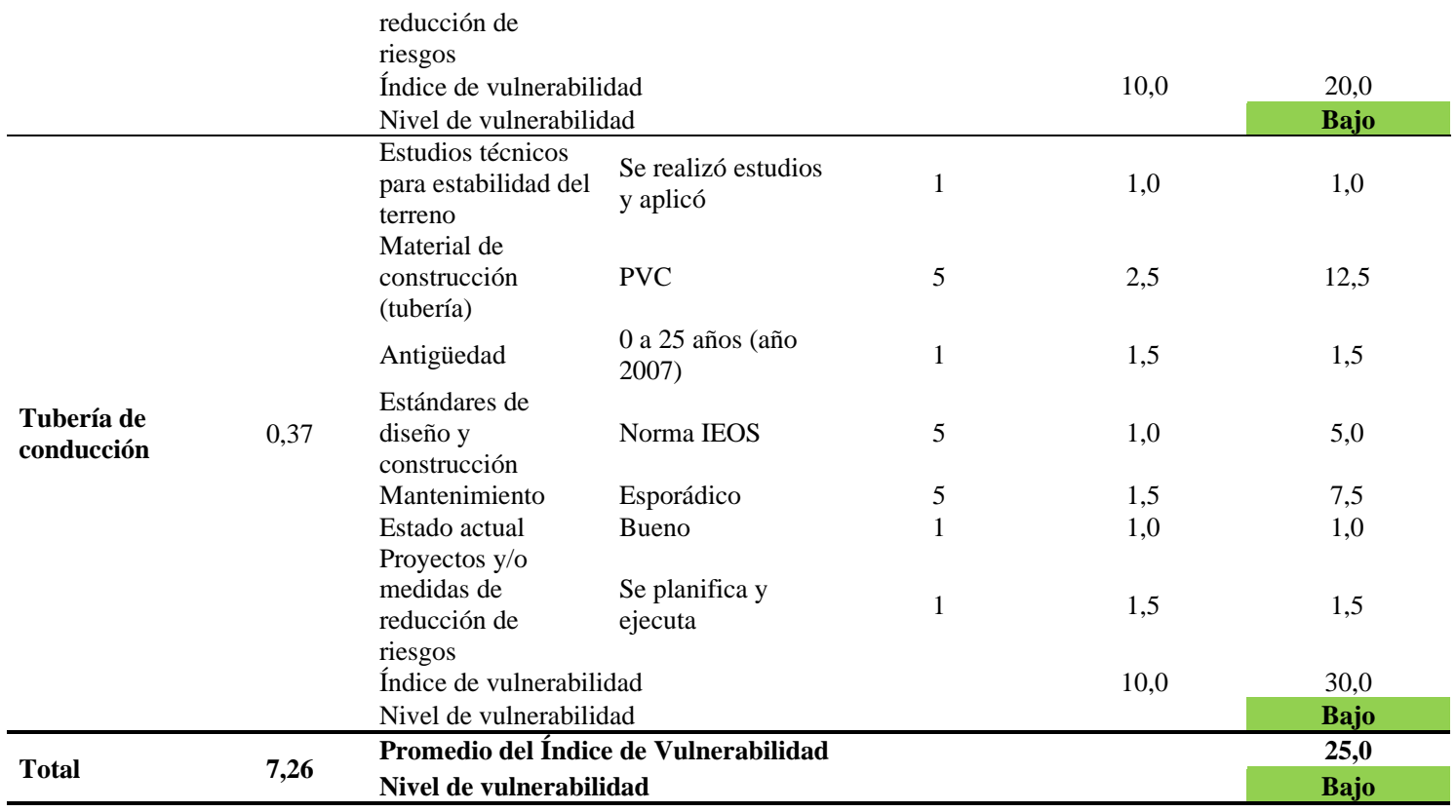

Tabla 8. Resultados Análisis de vulnerabilidad física del componente captación Fuente: Elaboración propia

\section{Análisis de vulnerabilidad y exposición del componente tratamiento}

Se analizó 3 plantas existentes como se observa en la tabla 9, la planta antigua de hormigón armado pese a ser construido en 1996, sin embargo por su estructura incide en el índice de 20 puntos (bajo), mientras que, la planta metálica prefabricada del año 2009, por su tipo de material el índice de 24 puntos (bajo), por su parte la planta nueva DAFFI del año 2015, por su tecnología y material posee el índice más bajo con 14 puntos (bajo); el índice promedio de este componente es de 19,3 puntos que representa el nivel de vulnerabilidad Bajo. En relación a la exposición a movimiento en masa, las plantas de tratamiento se encuentran en una zona media (ver tabla 12 y mapa 1).

\begin{tabular}{|c|c|c|c|c|c|c|}
\hline $\begin{array}{l}\text { Componente: } \\
\text { plantas de } \\
\text { tratamiento } \\
\end{array}$ & $\begin{array}{l}\text { Número de } \\
\text { plantas }\end{array}$ & Indicadores & $\begin{array}{l}\text { Condición del } \\
\text { sistema }\end{array}$ & $\begin{array}{l}\text { Valor de } \\
\text { indicador }\end{array}$ & $\begin{array}{c}\text { Peso } \\
\text { ponderación }\end{array}$ & $\begin{array}{c}\text { Valor } \\
\text { máximo }\end{array}$ \\
\hline \multirow{9}{*}{$\begin{array}{l}\text { Planta antigua de } \\
\text { hormigón armado }\end{array}$} & \multirow{9}{*}{1} & $\begin{array}{l}\text { Estudios técnicos para } \\
\text { cimentación }\end{array}$ & $\begin{array}{l}\text { Se realizó } \\
\text { estudios y aplicó }\end{array}$ & 1 & 1,0 & 1,0 \\
\hline & & $\begin{array}{l}\text { Material de } \\
\text { construcción }\end{array}$ & Hormigón & 1 & 2,5 & 2,5 \\
\hline & & Antigüedad & 25 a 40 años & 5 & 1,5 & 7,5 \\
\hline & & $\begin{array}{l}\text { Estándares de diseño y } \\
\text { construcción }\end{array}$ & Norma IEOS & 5 & 1,0 & 5,0 \\
\hline & & Mantenimiento & Planificado & 1 & 1,5 & 1,5 \\
\hline & & Estado actual & Bueno & 1 & 1,0 & 1,0 \\
\hline & & $\begin{array}{l}\text { Proyectos y/o medidas } \\
\text { de reducción de } \\
\text { riesgos }\end{array}$ & $\begin{array}{l}\text { Se planifica y } \\
\text { ejecuta }\end{array}$ & 1 & 1,5 & 1,5 \\
\hline & & Índice de vulnerabilidad & & & 10,0 & 20,0 \\
\hline & & Nivel de vulnerabilidad & & & & Bajo \\
\hline \multirow{3}{*}{$\begin{array}{l}\text { Planta metálica } \\
\text { prefabricada }\end{array}$} & \multirow{3}{*}{1} & $\begin{array}{l}\text { Estudios técnicos para } \\
\text { cimentación }\end{array}$ & $\begin{array}{l}\text { Se realizó } \\
\text { estudios y aplicó }\end{array}$ & 1 & 1,0 & 1,0 \\
\hline & & $\begin{array}{l}\text { Material de } \\
\text { construcción }\end{array}$ & Metálica & 5 & 2,5 & 12,5 \\
\hline & & Antigüedad & 0 a 25 años & 1 & 1,5 & 1,5 \\
\hline
\end{tabular}




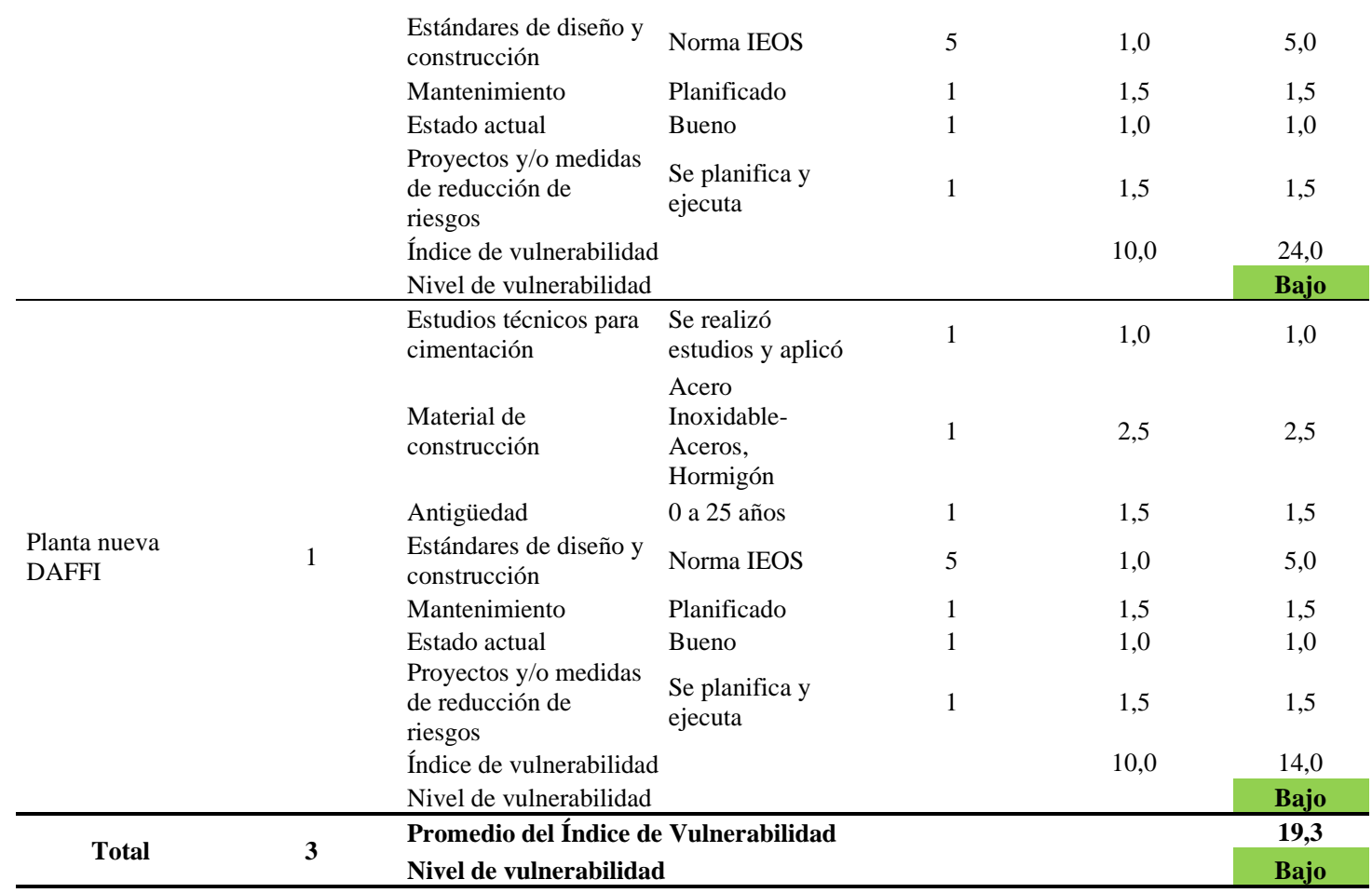

Tabla 9. Resultados Análisis de vulnerabilidad física del componente Planta de Tratamiento Fuente: Elaboración propia

\section{Análisis de vulnerabilidad y exposición del componente distribución}

Los tanques de reserva para distribución, los 2 tanques localizados en planta San Pedro y Santísima Trinidad, por ser de hormigón armado y menores a 25 años influyen en el índice de 18 punto (nivel bajo), mientras que, 1 tanque de la planta Antigua de Miraflores, pese a ser de hormigón, pero, por ser entre 25 a 40 años incide en el índice de 24 puntos (bajo); por su parte, los 7 tanques restante, pese a ser menores de 25 años, por ser de material ferro-cemento influyen en el índice de 28 punto (bajo). El promedio de los 10 tanques de reserva de distribución analizados es de 25,2 puntos que representa el nivel de vulnerabilidad bajo como se observa en la tabla 10. Mientras que, el análisis de exposición a movimiento en masa, el tanque de reserva de Santísima Trinidad se encuentra en una zona de alta y el $80 \%$ de los tanques se localizan en la zona media (ver tabla 12 y mapa 1).

\begin{tabular}{|c|c|c|c|c|c|c|}
\hline $\begin{array}{l}\text { Componente: } \\
\text { tanques de } \\
\text { Reserva } \\
\text { (distribución) }\end{array}$ & $\begin{array}{c}\text { Número } \\
\text { de } \\
\text { tanques }\end{array}$ & Indicadores & $\begin{array}{l}\text { Condición del } \\
\text { sistema }\end{array}$ & $\begin{array}{l}\text { Valor de } \\
\text { indicador }\end{array}$ & $\begin{array}{c}\text { Peso } \\
\text { ponderación }\end{array}$ & $\begin{array}{c}\text { Valor } \\
\text { máximo }\end{array}$ \\
\hline \multirow{3}{*}{$\begin{array}{l}\text { Tanques: Planta } \\
\text { San Pedro y } \\
\text { Santísima } \\
\text { Trinidad }\end{array}$} & \multirow{3}{*}{2} & $\begin{array}{l}\text { Estudios técnicos } \\
\text { para cimentación }\end{array}$ & $\begin{array}{l}\text { Se realizó } \\
\text { estudios, pero } \\
\text { no se aplicó }\end{array}$ & 5 & 1,0 & 5,0 \\
\hline & & $\begin{array}{l}\text { Material de } \\
\text { construcción }\end{array}$ & Hormigón & 1 & 2,5 & 2,5 \\
\hline & & Antigüedad & 0 a 25 años & 1 & 1,5 & 1,5 \\
\hline
\end{tabular}


Estándares de

diseño y

Norma IEOS

1,0

5,0

construcción

Mantenimiento

Planificado

1,5

1,5

Estado actual

Bueno

1,0

1,0

Proyectos y/o

medidas de

Se planifica y

ejecuta

1,5

riesgos

Índice de vulnerabilidad

10,0

18,0

Nivel de vulnerabilidad

\begin{tabular}{|c|c|c|c|c|c|c|}
\hline \multirow{9}{*}{$\begin{array}{l}\text { Tanques: Planta } \\
\text { Antigua de } \\
\text { Miraflores }\end{array}$} & \multirow{9}{*}{1} & $\begin{array}{l}\text { Estudios técnicos } \\
\text { para cimentación }\end{array}$ & $\begin{array}{l}\text { Se realizó } \\
\text { estudios, pero } \\
\text { no se aplicó }\end{array}$ & 5 & 1,0 & 5,0 \\
\hline & & $\begin{array}{l}\text { Material de } \\
\text { construcción }\end{array}$ & Hormigón & 1 & 2,5 & 2,5 \\
\hline & & Antigüedad & 25 a 40 años & 5 & 1,5 & 7,5 \\
\hline & & $\begin{array}{l}\text { Estándares de } \\
\text { diseño y } \\
\text { construcción }\end{array}$ & Norma IEOS & 5 & 1,0 & 5,0 \\
\hline & & Mantenimiento & Planificado & 1 & 1,5 & 1,5 \\
\hline & & Estado actual & Bueno & 1 & 1,0 & 1,0 \\
\hline & & $\begin{array}{l}\text { Proyectos y/o } \\
\text { medidas de } \\
\text { reducción de } \\
\text { riesgos }\end{array}$ & $\begin{array}{l}\text { Se planifica y } \\
\text { ejecuta }\end{array}$ & 1 & 1,5 & 1,5 \\
\hline & & \multirow{2}{*}{\multicolumn{3}{|c|}{$\begin{array}{l}\text { Índice de vulnerabilidad } \\
\text { Nivel de vulnerabilidad }\end{array}$}} & 10,0 & 24,0 \\
\hline & & & & & & Bajo \\
\hline \multirow{9}{*}{$\begin{array}{l}\text { Tanques: Reserva } \\
1 \text { y Reserva } 2 \text { de } \\
\text { San Pedro }\end{array}$} & \multirow{9}{*}{2} & $\begin{array}{l}\text { Estudios técnicos } \\
\text { para cimentación }\end{array}$ & $\begin{array}{l}\text { Se realizó } \\
\text { estudios, pero } \\
\text { no se aplicó }\end{array}$ & 5 & 1,0 & 5,0 \\
\hline & & $\begin{array}{l}\text { Material de } \\
\text { construcción }\end{array}$ & Ferro-cemento & 5 & 2,5 & 12,5 \\
\hline & & Antigüedad & 0 a 25 años & 1 & 1,5 & 1,5 \\
\hline & & $\begin{array}{l}\text { Estándares de } \\
\text { diseño y } \\
\text { construcción }\end{array}$ & Norma IEOS & 5 & 1,0 & 5,0 \\
\hline & & Mantenimiento & Planificado & 1 & 1,5 & 1,5 \\
\hline & & Estado actual & Bueno & 1 & 1,0 & 1,0 \\
\hline & & $\begin{array}{l}\text { Proyectos y/o } \\
\text { medidas de } \\
\text { reducción de } \\
\text { riesgos }\end{array}$ & $\begin{array}{l}\text { Se planifica y } \\
\text { ejecuta }\end{array}$ & 1 & 1,5 & 1,5 \\
\hline & & Índice de vulnerab & dad & & 10,0 & 28,0 \\
\hline & & Nivel de vulnerabi & & & & Bajo \\
\hline \multirow{8}{*}{$\begin{array}{l}\text { Tanque de } \\
\text { Reserva: Pan de } \\
\text { Azúcar 1, Pan de } \\
\text { Azúcar 2, Pan de } \\
\text { Azucar 2,1 }\end{array}$} & \multirow{8}{*}{3} & $\begin{array}{l}\text { Estudios técnicos } \\
\text { para cimentación }\end{array}$ & $\begin{array}{l}\text { Se realizó } \\
\text { estudios, pero } \\
\text { no se aplicó }\end{array}$ & 5 & 1,0 & 5,0 \\
\hline & & $\begin{array}{l}\text { Material de } \\
\text { construcción }\end{array}$ & Ferro-cemento & 5 & 2,5 & 12,5 \\
\hline & & Antigüedad & 0 a 25 años & 1 & 1,5 & 1,5 \\
\hline & & $\begin{array}{l}\text { Estándares de } \\
\text { diseño y } \\
\text { construcción }\end{array}$ & Norma IEOS & 5 & 1,0 & 5,0 \\
\hline & & Mantenimiento & Planificado & 1 & 1,5 & 1,5 \\
\hline & & Estado actual & Bueno & 1 & 1,0 & 1,0 \\
\hline & & $\begin{array}{l}\text { Proyectos y/o } \\
\text { medidas de } \\
\text { reducción de } \\
\text { riesgos }\end{array}$ & $\begin{array}{l}\text { Se planifica y } \\
\text { ejecuta }\end{array}$ & 1 & 1,5 & 1,5 \\
\hline & & \multicolumn{3}{|c|}{ Índice de vulnerabilidad } & 10,0 & 28,0 \\
\hline
\end{tabular}




\begin{tabular}{|c|c|c|c|c|c|c|}
\hline & & \multicolumn{4}{|c|}{ Nivel de vulnerabilidad } & \multirow{2}{*}{$\begin{array}{r}\text { Bajo } \\
5,0\end{array}$} \\
\hline \multirow{9}{*}{$\begin{array}{l}\text { Tanque de } \\
\text { Reserva: } \\
\text { Sigsicocha } 1 \text { y } 2\end{array}$} & \multirow{9}{*}{2} & $\begin{array}{l}\text { Estudios técnicos } \\
\text { para cimentación }\end{array}$ & $\begin{array}{l}\text { Se realizó } \\
\text { estudios, pero } \\
\text { no se aplicó }\end{array}$ & 5 & 1,0 & \\
\hline & & $\begin{array}{l}\text { Material de } \\
\text { construcción }\end{array}$ & Ferro-cemento & 5 & 2,5 & 12,5 \\
\hline & & Antigüedad & 0 a 25 años & 1 & 1,5 & 1,5 \\
\hline & & $\begin{array}{l}\text { Estándares de } \\
\text { diseño y } \\
\text { construcción }\end{array}$ & Norma IEOS & 5 & 1,0 & 5,0 \\
\hline & & Mantenimiento & Planificado & 1 & 1,5 & 1,5 \\
\hline & & Estado actual & Bueno & 1 & 1,0 & 1,0 \\
\hline & & $\begin{array}{l}\text { Proyectos y/o } \\
\text { medidas de } \\
\text { reducción de } \\
\text { riesgos }\end{array}$ & $\begin{array}{l}\text { Se planifica y } \\
\text { ejecuta }\end{array}$ & 1 & 1,5 & 1,5 \\
\hline & & \multirow{2}{*}{\multicolumn{2}{|c|}{$\begin{array}{l}\text { Índice de vulnerabilidad } \\
\text { Nivel de vulnerabilidad }\end{array}$}} & & 10,0 & 28,0 \\
\hline & & & & & & Bajo \\
\hline \multirow{2}{*}{ Total } & \multirow{2}{*}{10} & \multirow{2}{*}{\multicolumn{3}{|c|}{$\begin{array}{l}\text { Promedio del Índice de Vulnerabilidad } \\
\text { Nivel de vulnerabilidad }\end{array}$}} & & 25,2 \\
\hline & & & & & & Bajo \\
\hline
\end{tabular}

Tabla 10. Resultados Análisis de vulnerabilidad física del componente Tanques de Reserva distribución

Fuente: Elaboración propia

La red de distribución, la tubería de PVC por el tipo de material incide en el índice de 41,5 (nivel medio), mientras que, la tubería PVC-TOM, por ser de mayor vida útil que la anterior, influye en el índice de 31,5 (bajo), por su parte, la tubería de politubo por su material y antigüedad registra el índice de 60 punto (medio), de igual forma, la tubería de asbesto cemento y por su antigüedad posee el índice más alto con 67,5 puntos (nivel alto); el índice promedio de la red de distribución es de 48,4 puntos que representa un nivel de vulnerabilidad medio como se observa en la tabla 11. Con respecto al análisis de exposición a movimiento en masa, la red de tubería entre el tanque de tratamiento y los tanques de reserva de distribución, posee en su mayor parte nivel medio $(63,9 \%)$, seguido del nivel bajo $(21,1 \%)$ y nivel alto $(15,5 \%)$; mientras que los tanques de reserva, en la zona alta se localiza 1 tanque, 1 en la zona baja, y 8 en la zona media; por su parte, la red de distribución, en su orden registra niveles de exposición: media $(63,7 \%)$, baja $(21,1 \%)$ y alta $(15,2 \%)$ como muestra en la tabla 12 y mapa 1.

\begin{tabular}{|c|c|c|c|c|c|c|}
\hline $\begin{array}{l}\text { Componente: } \\
\text { red distribución }\end{array}$ & $\begin{array}{l}\text { Longitud } \\
\text { en km }\end{array}$ & Indicadores & $\begin{array}{l}\text { Condición del } \\
\text { sistema }\end{array}$ & $\begin{array}{l}\text { Valor de } \\
\text { indicador }\end{array}$ & $\begin{array}{c}\text { Peso } \\
\text { ponderación }\end{array}$ & $\begin{array}{c}\text { Valor } \\
\text { máximo }\end{array}$ \\
\hline \multirow{6}{*}{$\begin{array}{l}\text { Red de } \\
\text { distribución } \\
\text { nueva (tubería } \\
\text { con PVC) }\end{array}$} & \multirow{6}{*}{155,73} & $\begin{array}{l}\text { Estudios técnicos para } \\
\text { cimentación }\end{array}$ & $\begin{array}{l}\text { Se realizó } \\
\text { estudios, pero no } \\
\text { se aplicó }\end{array}$ & 5 & 1,0 & 5,0 \\
\hline & & Material de construcción & PVC & 5 & 2,5 & 12,5 \\
\hline & & Antigüedad & 0 a 25 años & 1 & 1,5 & 1,5 \\
\hline & & $\begin{array}{l}\text { Estándares de diseño y } \\
\text { construcción }\end{array}$ & Norma IEOS & 5 & 1,0 & 5,0 \\
\hline & & Mantenimiento & Planificado & 1 & 1,5 & 1,5 \\
\hline & & Estado actual & Bueno & 1 & 1,0 & 1,0 \\
\hline
\end{tabular}




\begin{tabular}{|c|c|c|c|c|c|c|}
\hline & & $\begin{array}{l}\text { Proyectos y/o medidas de } \\
\text { reducción de riesgos }\end{array}$ & $\begin{array}{l}\text { No se planifica ni } \\
\text { ejecuta }\end{array}$ & 10 & 1,5 & 15,0 \\
\hline & & Índice de vulnerabilidad & & & 10,0 & 41,5 \\
\hline & & Nivel de vulnerabilidad & & & & Medio \\
\hline & & $\begin{array}{l}\text { Estudios técnicos para } \\
\text { cimentación }\end{array}$ & $\begin{array}{l}\text { Se realizó } \\
\text { estudios, pero no } \\
\text { se aplicó }\end{array}$ & 5 & 1,0 & 5,0 \\
\hline & & Material de construcción & PVC - TOM & 1 & 2,5 & 2,5 \\
\hline & & Antigüedad & 0 a 25 años & 1 & 1,5 & 1,5 \\
\hline $\begin{array}{l}\text { Red de } \\
\text { distribución }\end{array}$ & 0,51 & $\begin{array}{l}\text { Estándares de diseño y } \\
\text { construcción }\end{array}$ & Norma IEOS & 5 & 1,0 & 5,0 \\
\hline con PVC-TOM) & & Mantenimiento & Planificado & 1 & 1,5 & 1,5 \\
\hline & & Estado actual & Bueno & 1 & 1,0 & 1,0 \\
\hline & & $\begin{array}{l}\text { Proyectos y/o medidas de } \\
\text { reducción de riesgos }\end{array}$ & $\begin{array}{l}\text { No se planifica ni } \\
\text { ejecuta }\end{array}$ & 10 & 1,5 & 15,0 \\
\hline & & Índice de vulnerabilidad & & & 10,0 & 31,5 \\
\hline & & Nivel de vulnerabilidad & & & & Bajo \\
\hline & & $\begin{array}{l}\text { Estudios técnicos para } \\
\text { cimentación }\end{array}$ & $\begin{array}{l}\text { Se realizó } \\
\text { estudios, pero no } \\
\text { se aplicó }\end{array}$ & 5 & 1,0 & 5,0 \\
\hline & & Material de construcción & asbesto cemento & 10 & 2,5 & 25,0 \\
\hline Red de & & Antigüedad & Mayor a 40 años & 10 & 1,5 & 15,0 \\
\hline $\begin{array}{l}\text { distribución } \\
\text { antigua (tubería } \\
\text { de asbesto }\end{array}$ & 0,33 & $\begin{array}{l}\text { Estándares de diseño y } \\
\text { construcción }\end{array}$ & Norma IEOS & 5 & 1,0 & 5,0 \\
\hline cemento) & & Mantenimiento & Planificado & 1 & 1,5 & 1,5 \\
\hline & & Estado actual & Bueno & 1 & 1,0 & 1,0 \\
\hline & & $\begin{array}{l}\text { Proyectos y/o medidas de } \\
\text { reducción de riesgos }\end{array}$ & $\begin{array}{l}\text { No se planifica ni } \\
\text { ejecuta }\end{array}$ & 10 & 1,5 & 15,0 \\
\hline & & Índice de vulnerabilidad & & & 10,0 & 67,5 \\
\hline & & Nivel de vulnerabilidad & & & & Alto \\
\hline & & $\begin{array}{l}\text { Estudios técnicos para } \\
\text { cimentación }\end{array}$ & $\begin{array}{l}\text { Se realizó } \\
\text { estudios, pero no } \\
\text { se aplicó }\end{array}$ & 5 & 1,0 & 5,0 \\
\hline & & Material de construcción & Politubo & 10 & 2,5 & 25,0 \\
\hline & & Antigüedad & De 25 a 40 años & 5 & 1,5 & 7,5 \\
\hline $\begin{array}{l}\text { Red de } \\
\text { distribución } \\
\text { antigua (tubería }\end{array}$ & 0,28 & $\begin{array}{l}\text { Estándares de diseño y } \\
\text { construcción }\end{array}$ & Norma IEOS & 5 & 1,0 & 5,0 \\
\hline de politubo) & & Mantenimiento & Planificado & 1 & 1,5 & 1,5 \\
\hline & & Estado actual & Bueno & 1 & 1,0 & 1,0 \\
\hline & & $\begin{array}{l}\text { Proyectos y/o medidas de } \\
\text { reducción de riesgos }\end{array}$ & $\begin{array}{l}\text { No se planifica ni } \\
\text { ejecuta }\end{array}$ & 10 & 1,5 & 15,0 \\
\hline & & Índice de vulnerabilidad & & & 10,0 & 60,0 \\
\hline & & Nivel de vulnerabilidad & & & & Medio \\
\hline & & $\begin{array}{l}\text { Estudios técnicos para } \\
\text { cimentación }\end{array}$ & $\begin{array}{l}\text { Se realizó } \\
\text { estudios, pero no } \\
\text { se aplicó }\end{array}$ & 5 & 1,0 & 5,0 \\
\hline $\begin{array}{l}\text { Red de } \\
\text { distribución }\end{array}$ & & Material de construcción & $\mathrm{PVC}$ & 5 & 2,5 & 12,5 \\
\hline Tanques de & 7,037 & Antigüedad & 0 a 25 años & 1 & 1,5 & 1,5 \\
\hline $\begin{array}{l}\text { Reserva (tubería } \\
\text { con PVC) }\end{array}$ & & $\begin{array}{l}\text { Estándares de diseño y } \\
\text { construcción }\end{array}$ & Norma IEOS & 5 & 1,0 & 5,0 \\
\hline & & Mantenimiento & Planificado & 1 & 1,5 & 1,5 \\
\hline & & Estado actual & Bueno & 1 & 1,0 & 1,0 \\
\hline
\end{tabular}




\begin{tabular}{|c|c|c|c|c|c|c|}
\hline & & $\begin{array}{l}\text { Proyectos y/o medidas de } \\
\text { reducción de riesgos }\end{array}$ & $\begin{array}{l}\text { No se planifica ni } \\
\text { ejecuta }\end{array}$ & 10 & 1,5 & 15,0 \\
\hline & & \multirow{2}{*}{\multicolumn{4}{|c|}{$\begin{array}{l}\text { Índice de vulnerabilidad } \\
\text { Nivel de vulnerabilidad }\end{array}$}} & 41,5 \\
\hline & & & & & & Medio \\
\hline \multirow{2}{*}{ Total } & \multirow{2}{*}{163,887} & \multirow{2}{*}{\multicolumn{4}{|c|}{$\begin{array}{l}\text { Promedio del Índice de Vulnerabilidad } \\
\text { Nivel de vulnerabilidad }\end{array}$}} & 48,4 \\
\hline & & & & & & Medio \\
\hline
\end{tabular}

Tabla 11. Resultados Análisis de vulnerabilidad física del componente distribución Fuente: Elaboración propia

\begin{tabular}{|c|c|c|c|c|c|c|c|c|c|}
\hline \multirow[b]{2}{*}{$\begin{array}{c}\text { Componentes } \\
\text { del sistema de } \\
\text { agua }\end{array}$} & \multirow[b]{2}{*}{$\begin{array}{c}\text { Infraestructura del } \\
\text { Sistema }\end{array}$} & \multicolumn{6}{|c|}{ Nivel exposición a movimiento en masa } & \\
\hline & & $\begin{array}{l}\text { Al } \\
\text { Long. en } \\
\text { km ó } \\
\text { número } \\
\end{array}$ & $\%$ & $\begin{array}{c}\text { Med } \\
\text { Long. en } \\
\text { km ó } \\
\text { número } \\
\end{array}$ & $\%$ & $\begin{array}{l}\text { Baja } \\
\text { Long. en } \\
\text { km ó } \\
\text { número } \\
\end{array}$ & $\%$ & $\begin{array}{c}\text { Long. en } \\
\text { km ó } \\
\text { número } \\
\end{array}$ & $\%$ \\
\hline Captación & $\begin{array}{l}\text { Tanques de } \\
\text { captación }\end{array}$ & 1,0 & 100,0 & 0,0 & 0,0 & 0,0 & 0,0 & 1,000 & 100,0 \\
\hline Conducción & Línea de conducción & 3,75 & 51,7 & 3,30 & 45,4 & 0,21 & 3,0 & 7,262 & 100,0 \\
\hline Tratamiento & Planta de tratamiento & 0,0 & 0,0 & 1,0 & 100,0 & 0,0 & 0,0 & 1,000 & 100,0 \\
\hline \multirow{3}{*}{ Distribución } & $\begin{array}{l}\text { Red distribución } \\
\text { reservas }\end{array}$ & 1,1 & 15,0 & 4,50 & 63,9 & 1,48 & 21,1 & 7,037 & 100,0 \\
\hline & Tanques de reserva & 1,0 & 10,0 & 8,0 & 80,0 & 1,0 & 10,0 & 10,000 & 100,0 \\
\hline & Red de distribución & 23,9 & 15,2 & 99,9 & 63,7 & 33,0 & 21,1 & 156,850 & 100,0 \\
\hline
\end{tabular}

Tabla 12. Resultados análisis de Nivel exposición a movimientos en masa del sistema de agua potable Culebrillas

Fuente: Elaboración propia

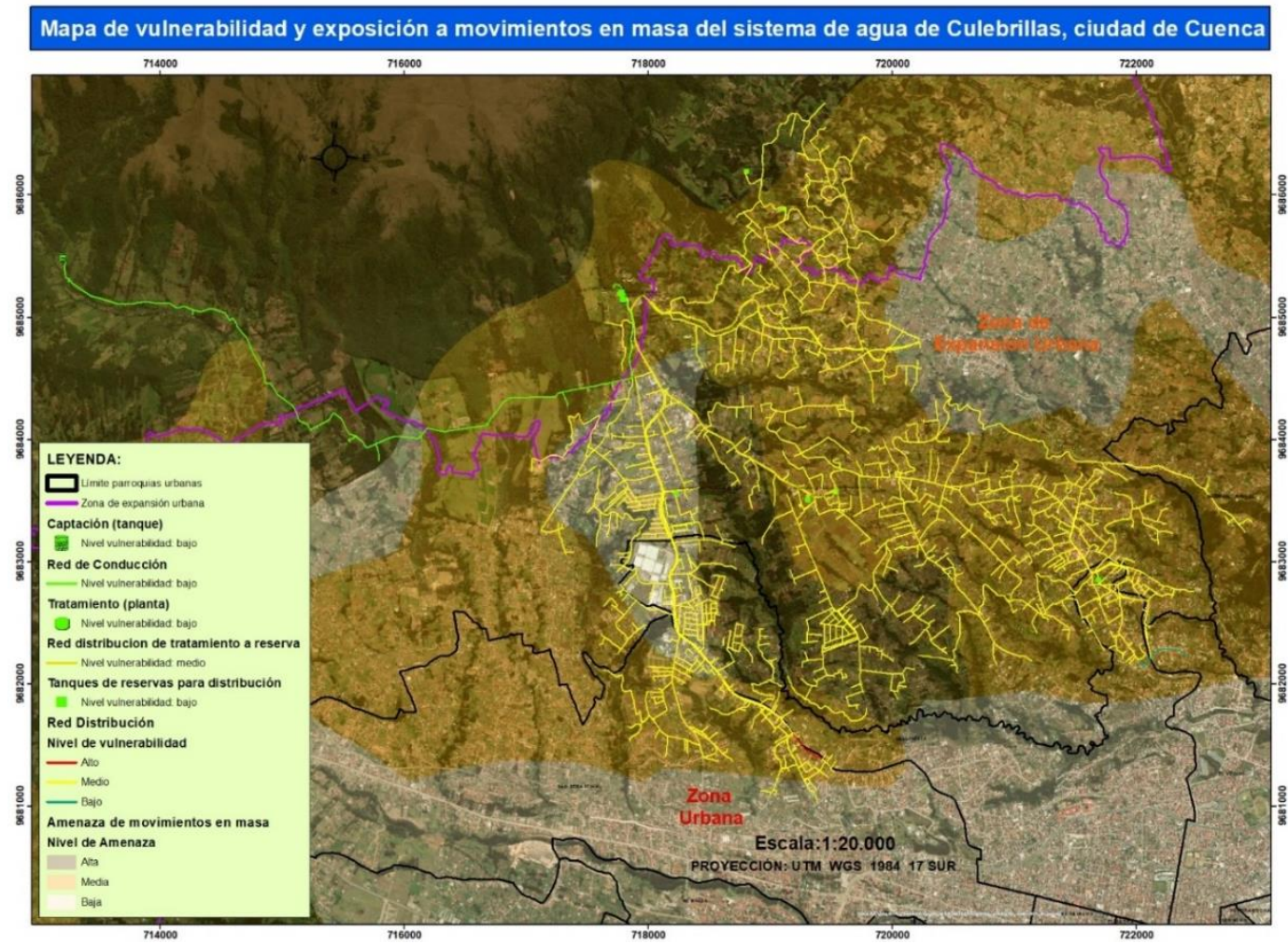

Mapa 1. Resultados Análisis de Riesgo a Movimientos en Masa del Sistema de Agua Culebrillas Fuente: Elaboración propia 


\section{Conclusiones.}

- Se evaluó y se obtuvo los índices y niveles de vulnerabilidad de los componentes de: captación, conducción, tratamiento y la distribución del sistema de agua potable Culebrillas que presenta en promedio el índice y niveles de vulnerabilidad física baja y media; debido principalmente a que los componentes del sistema cumplen en su mayoría con los parámetros en la fase de diseño y construcción; sin embargo, existen indicadores que no disponen de información o no se cumplen como los proyectos y/o medidas de reducción de riesgos y el mantenimiento es esporádico.

- Las tuberías de asbesto cemento en tramos de la red de distribución, debido a su antigüedad ya cumplieron con su vida útil, por ello causan un nivel de vulnerabilidad alto al componente del sistema; además, el desprendimiento y suspensión de fibras de amianto en el interior de la tubería podrían poner en riesgo a la salud, por lo que se requiere con prioridad ser remplazadas.

- Según el mapa de amenaza de movimientos en masa se estableció que la captación y en su mayor parte la línea de conducción del sistema de agua potable Culebrillas, están asentadas en una zona de alta exposición, por lo que se debe incluir medidas como estabilización de taludes y refuerzos de componentes para la reducción del riesgo de afectación por deslizamientos.

- Los resultados de la investigación constituyen un aporte para la actualización de los Planes de Gestión del Riesgo de la Empresa Pública de Telecomunicaciones, Agua Potable y Alcantarillado de Cuenca, lo que contribuirá a establecer medidas y estrategias de reducción en la infraestructura del sistema de agua potable Culebrillas. Además, se constituye en un modelo piloto para evaluar los otros sistemas que abastece a la ciudad de Cuenca, así como, se podría replicar en otros centros poblados del país.

\section{Agradecimientos.}

El presente artículo es parte del trabajo de investigación y titulación del Programa de Maestría en Construcción con Mención en Administración de la Construcción Sustentable de la Universidad Católica de Cuenca, por ello agradecemos a todos y cada uno de los instructores por los conocimientos e información brindados para la elaboración del trabajo; así como, el agradecimiento a la Empresa Pública de Telecomunicaciones, Agua Potable y Alcantarillado de Cuenca, por las facilidades brindadas en el presente estudio.

\section{Referencias bibliográficas.}

(PNUD)., E. S. N. de G. de R. (SNGR); P. de las N. U. para el D. (2012). Documento: Guía de implementación análisis de vulnerabilidad a nivel municipal. Guía de Implementación Análisis de Vulnerabilidad a Nivel Municipal. http://bvpad.indeci.gob.pe/doc/pdf/esp/doc2201/doc2201.htm 
Carrizosa, M., Cohen, M., Gutman, M., Leite, F., López, D., Nesprias, J., ... Versace, I. (2019). E. el riesgo. N. prácticas de resiliencia urbana en A. L. C. C. R. from http://scioteca. caf. com/handle/123456789/141. (2019). 9 lecciones para reducir el efecto de desastres naturales en las ciudades latinoamericanas. Carrizosa, M., Cohen, M., Gutman, M., Leite, F., López, D., Nesprias, J., ... Versace, I. (2019). Enfrentar El Riesgo. Nuevas Prácticas de Resiliencia Urbana En América Latina. Caracas: CAF. Retrieved from Http://Scioteca.Caf.Com/Handle/123456789/1416. https://www.notimerica.com/sociedad/noticia-lecciones-reducir-efecto-desastresnaturales-ciudades-latinoamericanas-20190411145443.html

Comisión Nacional del Agua. (2007). Manual de Agua Potable, Alcantarillado y Saneamiento Diseño de Redes de Distribución de Agua Potable. In Comisión Nacional del Agua. https://sswm.info/sites/default/files/reference_attachments/CONAGUA s.f.a. Diseño de redes de distribución de agua potable.pdf

Decisión. (2018). GLOSARIO DE TÉRMINOS Y CONCEPTOS DE LA GESTIÓN DEL RIESGO DE DESASTRES PARA LOS PAÍSES MIEMBROS DE LA COMUNIDAD ANDINA.

Etapa EP. (2021). https://www.etapa.net.ec/principal/agua-potable/planesmaestros/area-de-influencia

Gnavi, L., Taddia, G., \& Russo, S. L. (2015). Engineering geology for society and territory - Volume 6: Applied geology for major engineering projects. Assessment and Risk Management for Integrated Water Services. In Engineering Geology for Society and Territory-Volume 6 (Pp. 653-656). Springer, Cham., 6(Snfa 2007), 11082. https://doi.org/10.1007/978-3-319-09060-3

Jimenez, J. 2013. (2013). Manual para el diseño de sistemas de agua potable y alcantarillado sanitario, Facultad de ingeniería civil campus Xalapa Universidad Veracruzana.

MAGAP. (2014). Archivos de Información Geográfica - Sistema Nacional de Información. INFORMACIÓN 1:250.000 Actualización: 31/Dic/2014. https://sni.gob.ec/coberturas

OPS/OMS. (1998). Mitigación de desastres naturales en sistemas de agua potable y alcantarillado sanitario Guías para el análisis de vulnerabilidad. 100.

Paucar, A. 2016. (2016). Modelo Para La Articulación De La Gestión Del Riesgo En El Proceso De Ordenamiento Territorial De La Ciudad De Guaranda / Ecuador (Vol. 17, Issue Diciembre).

Piedra, A. (2017). Del Sistema De Potable Para La Ciudad De Operación Y. 291. https://maeazuay.files.wordpress.com/2017/03/estudio-ambiental-expost-delsistema-de-abastecimiento-de-agua-potable-para-la-ciudad-de-cuenca-en-su-etapade-operacic3b3n-y-mantenimiento.pdf

Servicio Nacional de Gestión de Riesgos y Emergencias. (2019). Lineamientos para incluir la gestión del riesgo de desastres en el PDOT Territorial. Lineamientos Para 
Incluir La Gestión Del Riesgo de Desastres En El PDOT Territorial, 80. https://www.planificacion.gob.ec/wp-content/uploads/downloads/2019/09/Caja-deherramientas-Riesgos.pdf

Sweya, L. N., \& Wilkinson, S. (2021). Tool development to measure the resilience of water supply systems in Tanzania: Economic dimension. Jamba: Journal of Disaster Risk Studies, 13(1), 1-9. https://doi.org/10.4102/JAMBA.V12I1.860

Villacorta, S., Fidel, L., \& Zavala Carrión, B. (2012). Mapa de Susceptibilidad Por Remoción en Masa de Suelos y Rocas. Revista de La Asociación Geológica Argentina, 69(3),

393-399. http://snet.gob.sv/ver/geologia/amenaza+deslizamientos/

Vivienda, M. de D. U. y. (2003). Guías técnicas para la reducción de la vulnerabilidad en los sistemas de agua potable $y$ saneamiento. http://cidbimena.desastres.hn/filemgmt/files/doc14793.pdf 


\section{PARA CITAR EL ARTÍCULO INDEXADO.}

Moscoso Vintimlla, G. M., Paucar Camacho, J. A., \& Solano Peláez, J. L. (2021). Vulnerabilidad física y exposición ante la amenaza de movimientos en masa del Sistema de Agua Potable Culebrillas de la Ciudad de Cuenca . Ciencia Digital, 5(2), 46-66. https://doi.org/10.33262/cienciadigital.v5i2.1573

\section{¿Ciencia}

El artículo que se publica es de exclusiva responsabilidad de los autores y no necesariamente reflejan el pensamiento de la Revista Ciencia Digital.

El artículo queda en propiedad de la revista y, por tanto, su publicación parcial y/o total en otro medio tiene que ser autorizado por el director de la Revista Ciencia Digital.
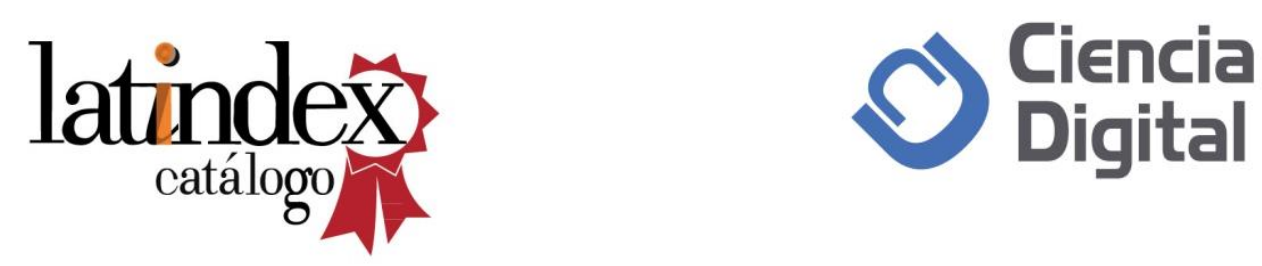